\title{
Interaction of iron ions with melanin*
}

\author{
Andrzej Żądłoø, Tadeusz Sarna \\ Department of Biophysics, Faculty of Biochemistry, Biophysics and Biotechnology, Jagiellonian University, Kraków, Poland
}

One of the antioxidant roles of melanin is binding redoxactive transition metal ions. The aim of this study was to examine the redox reactions accompanying iron binding by melanin. Two kinds of synthetic eumelanin were mixed with iron (II) and iron (III) in the presence and absence of citrate and ADP in the aerobic and anaerobic system. The iron binding was examined by electron paramagnetic resonance (EPR) spectroscopy and thiocyanate assay. Obtained results indicate that although melanin reduces iron (III) that is unbound to this polymer, binding of iron (II) is accompanied by its oxidation by melanin.

Key words: melanin, iron, oxidation, saturation curves

Received: 18 October, 2019; revised: 19 November, 2019; accepted: 01 December, 2019; available on-line: 11 December, 2019

๑e-mail: andrzej.zadlo@uj.edu.pl

* Some of results shown in this paper were presented at XXII International Pigment Cell Conference, Singapore 4-7 September 2014 XLII Szkoła Zimowa, Zakopane, Poland, 10-14 February 2015 and XXVI International EPR Seminar 2015, Graz, Austria, 8-10 Jun 2015. Acknowledgements of Financial Support: This work was supported by National Science Center grant (grant 2012/07/D/ST4/02211). Abbreviations: ADP, adenosine 5'-diphosphate; DMa, synthetic eumelanin prepared by autooxidation of DOPA; DMt, synthetic eumelanin prepared by DOPA oxidation catalyzed by tyrosinase; DOPA,3,4-dihydroxyphenylalanine; EPR, electron paramagnetic resonance; $P$, half-power (microwave power at which the first derivative amplitude is reduced to half of its unsaturated value); PBS, phosphate buffered saline.

\section{INTRODUCTION}

Although melanin is well known as photoprotector (Meredith \& Sarna, 2006; Brenner \& Hearing, 2008; d'Ischia et al., 2015), its antioxidant action is also noteworthy. One of the antioxidant roles of melanin is binding redox-active transition metal ions (Pilas et al., 1988), (Kaczara et al., 2012). On the other hand, melanin was shown to be prooxidant in the presence of strong chelators such as EDTA or an excessive amount of iron $(\mathrm{Ko}-$ rytowski et al., 1987; Pilas et al., 1988). Such prooxidant action was based on the reduction of iron (III) that was not bound to melanin. Iron is one of the most ubiquitous metals in the body. Therefore, the elucidation of the mechanism of interaction of melanin with iron may be the key to better understand such pathologies as agerelated macular degeneration (ARMD), skin melanoma or Parkinson's disease (PD), which were proposed to be based on oxidative stress of pigmented cells (Sarna, 1992; Beatty et al., 2000; Sarna et al., 2003; Zecca et al., 2003; Wood et al., 2006; Zecca et al., 2008; Noonan et al., 2012). The aim of this research was to examine the changes of the oxidation state of iron accompanying its binding to melanin. A water-soluble synthetic model of eumelanin prepared by DOPA autooxidation (DMa) and insoluble synthetic model of eumelanin prepared by enzymatic oxidation of DOPA (DMt) were mixed with salts of iron (II) and iron (III) or their complexes with citrate and ADP in the aerobic and anaerobic system.

\section{MATERIAL AND METHODS}

Reagents. All chemicals were reagent grade or better and used as supplied. Water was deionized by a millipore system (Millipore S A. 67120 Molsheim, France), citric acid solution and PBS prepared using this water were additionally treated with Chelex-100 to remove the traces of metal ions.

Preparation of synthetic eumelanins. Water-soluble model of eumelanin (DMa) was prepared by autooxidation of DOPA (Felix et al., 1978) and purified by a modified method described previously (Szewczyk et al., 2016). In brief, $25 \mathrm{~g}$ of D,L- $\beta$-dihydroxyphenylalanine (D,L-DOPA) was dissolved in 51 of water and alkalized to $\mathrm{pH} 8$ by $25 \%$ ammonia. The solution was stirred and air-bubbled for three days. Every several hours the $\mathrm{pH}$ was corrected to 8.0 by the addition of small amounts of ammonia. Then the solution was stirred without airbubbling for the next three days. After that, the solution was acidified to $\mathrm{pH} 2.5$ with hydrochloric acid and centrifuged at $4040 \times g$ for 10 minutes. The obtained precipitate was washed 8 times with water acidified to $\mathrm{pH}$ 2.5 and once with non-acidified water. The precipitate was suspended in about $0.5 \mathrm{l}$ of water, placed in a dialysis bag ( $12000 \mathrm{u})$ and dialyzed for 12 days against 51 of water with four changes of the water. DMa was quantified by determination of its dry mass. This melanin precipitated only in the acidic $\mathrm{pH}$. At neutral $\mathrm{pH}$ it was soluble in water, the size of particles of DMa was determined to be about $20 \mathrm{~nm}$ (Zadlo et al., 2017) and melanin did not show any tendency to aggregate.

Insoluble model of eumelanin, prepared by enzymatic oxidation of DOPA (DMt), was prepared as follows: $2 \mathrm{~g}$ of L- $\beta$-dihydroxyphenylalanine (L-DOPA) was dissolved in $995 \mathrm{ml}$ of $0.1 \mathrm{M} \mathrm{Na} / \mathrm{K}$ phosphate buffer $(\mathrm{pH}$ 6.8). The solution was vigorously stirred for at least 10 minutes. 223000 units of tyrosinase were dissolved in $5 \mathrm{ml}$ of phosphate buffer and added to the solution of L-DOPA. The mixture was bubbled with air at $37^{\circ} \mathrm{C}$ for $24 \mathrm{~h}$. Then the mixture was centrifuged for $0.5 \mathrm{~h}$ at $13000 \times g$ at $4^{\circ} \mathrm{C}$. The precipitate was suspended in 300 $\mathrm{ml}$ of water and centrifuged under the same conditions. Such a washing procedure was carried out seven times. Finally, the precipitate was suspended in $38 \mathrm{ml}$ of water. DMt was quantified in the same way as DMa. This melanin was insoluble in water even at neutral $\mathrm{pH}$ and it sedimented even without centrifugation.

Preparation of iron and copper complexes with melanin. Iron complexes with melanin were prepared either using complexes with citrate and ADP or using 
free salts. Some comparative experiments were carried out using copper (II) complexes with citrate. Iron (II) and copper (II) complexes with citrate were prepared by addition of $0.1 \mathrm{M}$ citric acid to $0.025 \mathrm{M}$ ferrous sulphate or cupric sulphate in $10^{-4} \mathrm{M} \mathrm{H}_{2} \mathrm{SO}_{4}$. Under such conditions, citrate:metal molar ratio was $2: 1$. Then the $\mathrm{pH}$ was adjusted to 7 by drop-wise addition of $1 \mathrm{M} \mathrm{NaOH}$. Finally, water was added, adjusting the metal ion concentration to $10 \mathrm{mM}$. Iron (III) complexes were prepared in a similar manner except that $0.025 \mathrm{M}$ ferric chloride was in $0.02 \mathrm{M}$ hydrochloric acid. Iron complex with ADP was prepared similarly but ADP was acidified to $\mathrm{pH} 2$ before the addition of iron salt and the molar ratio ADP:Fe was 4:1. The final concentration of the iron complexes with ADP was $2 \mathrm{mM}$. The prepared citrate or ADP complexes were added to $4 \mathrm{mg} / \mathrm{ml}$ melanin solution adjusted to $\mathrm{pH}$ 7.4. The mixture was diluted with water to melanin concentration $2 \mathrm{mg} / \mathrm{ml}$ and metal ion concentration $0.358 \mathrm{mM}$ i.e. $1 \%(\mathrm{w} / \mathrm{w})$ in the case of iron and $1.14 \%(\mathrm{w} / \mathrm{w})$ in the case of copper. After $0.5 \mathrm{~h}$ of incubation, the $\mathrm{pH}$ was readjusted to 7.4 and the mixture was further incubated at room temperature in the dark. Iron complex with ADP was added only to DMt. In the case of the iron complex with ADP, melanin samples were washed three times after 0.5 hours of incubation. As a result, the data for supernatant from melanin with iron complex with ADP are limited to time $0.5 \mathrm{~h}$ (Fig. 3B). A control sample without iron was prepared in a similar manner except for the addition of citrate without iron. Preparation of iron complex with melanin using iron (II) salt without citrate and ADP was done as described in (Zadlo et al., 2017). In brief, such amount of water and $0.025 \mathrm{M}$ ferrous sulphate in $10^{-4} \mathrm{M} \mathrm{H}_{2} \mathrm{SO}_{4}$ was added to $4 \mathrm{mg} / \mathrm{ml}$ melanin adjusted to $\mathrm{pH} 5$ that the final melanin concentration was $2 \mathrm{mg} / \mathrm{ml}$ and iron concentration was $0.358 \mathrm{mM}$ i.e. $1 \%$ (w/w). After $0.5 \mathrm{~h}$ of incubation, the $\mathrm{pH}$ was adjusted to 7.4 and treated similarly as during addition of iron complex with citrate or ADP. The control melanin was prepared similarly except for the addition of ferrous sulphate. Complexes of iron (III) with melanin were prepared in the following manner: $0.025 \mathrm{M}$ solution of ferric chloride in $0.02 \mathrm{M}$ hydrochloric acid was added to the diluted solution of melanin acidified to $\mathrm{pH}$ 2. The $\mathrm{pH}$ of such samples was increased in three steps i.e. after adjustment to $\mathrm{pH} 4$ and $\mathrm{pH} 6$ the sample was incubated for at least two hours before the further increase of $\mathrm{pH}$. Finally, the $\mathrm{pH}$ was increased to 7.4. There was additional control melanin for iron (III) treated analogously as melanin with iron (III) except for the addition of ferric chloride.

For the preparation of iron (II) solutions, $10^{-4} \mathrm{M}$ $\mathrm{H}_{2} \mathrm{SO}_{4}$ or $0.1 \mathrm{M}$ citrate were saturated with argon by bubbling for at least 0.5 hours. The results presented in Fig. $2 \mathrm{~B}$ and Fig. 4 were obtained using argon-saturated melanin.

Photoreduction of iron (III) and copper (II). Photoreduction of metal ions bound to melanin was carried out using the rose bengal/ $\beta-\mathrm{NADH}$ system (Korytowski $\&$ Sarna, 1990) where, upon photoexcitation of the dye, two strongly reducing radicals (Rose Bengal- and NAD) are formed (Lambert et al., 1990). A mixture containing $0.5 \mathrm{mM}$ rose bengal, $2.5 \mathrm{mM} \beta-\mathrm{NADH}$ and $1 \mathrm{mg} / \mathrm{ml}$ $\mathrm{DMa}$ with and without $1 \%$ (w/w) iron (III) or $\mathrm{Cu}$ (II) in PBS was irradiated with $516-586 \mathrm{~nm}\left(50 \mathrm{~mW} / \mathrm{cm}^{2}\right)$ light originating from XBO 450 short-arc xenon lamp equipped with $\mathrm{CuSO}_{4}$ filter and Green additive dichroic filter 585FD62-25 (Andover Corporation, Salem, USA). Irradiation was carried out in a closed spectrofluorimetric cuvette. Before irradiation, the sample was saturated with argon for at least $0.5 \mathrm{~h}$. The initial volume of the sample was $1 \mathrm{ml}$. During irradiation, the sample was gently stirred. Before irradiation and after 20 minutes of irradiation, $0.2 \mathrm{ml}$ of the mixture was withdrawn for EPR spectroscopy examination.

Electron paramagnetic resonance (EPR) spectroscopy. EPR spectroscopy was done using Bruker EMXAA EPR spectrometer (Bruker BioSpin, Rheinstetten, Germany). The efficiency of melanin-iron interaction was determined by measurements of the influence of iron on microwave power saturation of the EPR signal of melanin. Such measurements were carried out at room temperature using EPR flat cell $(0.3 \mathrm{~mm}$ thickness and $8 \mathrm{~mm}$ width). Just before EPR measurements, the sample $\mathrm{pH}$ was adjusted to 7.4. Typical instrumental settings were: modulation amplitude $0.305 \mathrm{mT}$; center field $339.2 \mathrm{mT}$; scan range $5 \mathrm{mT}$; scan time $42 \mathrm{~s}$ and time constant $327.7 \mu$ s. Microwave power was selected in the range of 0.00839 to $211 \mathrm{~mW}$. If signal:noise ratio was greater than 20, the amplitude of melanin EPR signal was determined digitally, otherwise, it was determined manually. The amplitude (Fig. 1A) was plotted against the square root of microwave power and half- power $\left(\mathrm{P}_{1 / 2}\right)$ was determined from the fit of the equation:

$\mathrm{f}(\mathrm{x})=\mathrm{A} \cdot \mathrm{x} \cdot\left[1+\left(2^{1 / \varepsilon}-1\right) \cdot \mathrm{x}^{2} / \mathrm{P}_{1 / 2}\right]^{-\varepsilon}$

(Altenbach et al., 1994) (Fig. 1B), where $\mathrm{x}$ is the square root of microwave power, $\mathrm{f}(\mathrm{x})$ is EPR signal amplitude, $\mathrm{A}$ is the initial slope, $\varepsilon$ is the homogeneity coefficient and $\mathrm{P}_{1 / 2}$ is the half-power i.e. microwave power, at which the first derivative amplitude (Fig. 1A) is reduced to the half of its unsaturated value.

The EPR signals of iron (III) and copper (II) bound to melanin were measured at $77 \mathrm{~K}$. Iron measurements were carried out at modulation amplitude $0.805 \mathrm{mT}$; center field $158.49 \mathrm{mT}$; scan range 50-100 mT; scan time 42-84 s; time constant $327.7 \mu \mathrm{s}$ and microwave power $5.29 \mathrm{~mW}$. The final EPR spectra of iron were taken from averaging 5-10 scans. Copper was measured at modulation amplitude $0.805 \mathrm{mT}$; center field 300 $\mathrm{m} T$; scan range $100 \mathrm{~m}$ T; scan time $42 \mathrm{~s}$; time constant $327.7 \mu$ s and microwave power $5.29 \mathrm{~mW}$. The final EPR spectra of copper were averages from 10 scans.
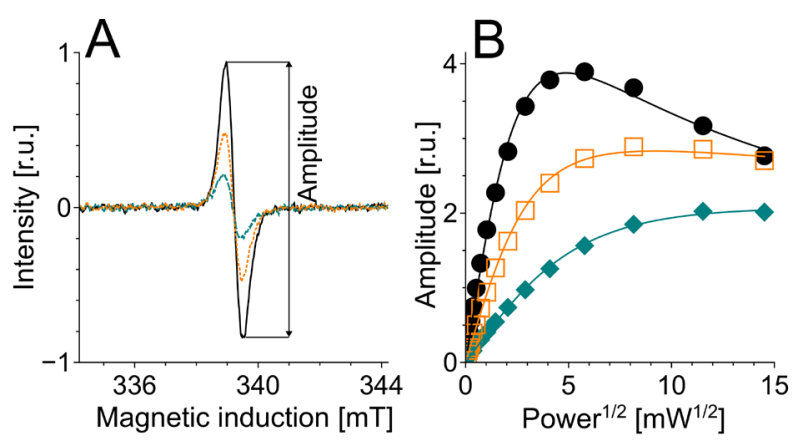

Figure 1. The effect of iron on EPR signal of $2 \mathrm{mg} / \mathrm{ml}$ DMt after $24 \mathrm{~h}$ of incubation with iron complex with citrate.

(A) EPR spectra of melanin registered at microwave power $1.06 \mathrm{~mW}$ for control melanin only with citrate (continuous line) or melanin with citrate complex of iron (II) (broken line) or iron (III) (dotted line). (B) melanin signal amplitude plotted against the square root of microwave power and fitted with the following function: $f(x)=A \cdot x \cdot\left[1+\left(2^{1 / \varepsilon}-1\right) \cdot x^{2} / P_{1 / 2}\right]^{-\varepsilon}$ (Altenbach et al., 1994) as described in the "Material and methods" section. Filled circles - control melanin without iron, filled diamonds - melanin with iron (II), open squares - melanin with iron (III). 
Determination of the unbound iron. $0.2 \mathrm{ml}$ of the sample was centrifuged at $20,871 \times g$ for 5 minutes. $0.18 \mathrm{ml}$ of the supernatant was acidified by addition of $0.01 \mathrm{ml}$ of $2 \mathrm{M} \mathrm{HCl}$. After the addition of $0.01 \mathrm{ml}$ of $0.1 \mathrm{M} \mathrm{H}_{2} \mathrm{O}_{2}$, the sample was heated at $100^{\circ} \mathrm{C}$ for 15 minutes to oxidize iron. Iron (III) was determined by thiocyanate assay as previously described (Żądło, 2019). Determination of the unbound iron was limited only to $\mathrm{DMt}$ which is insoluble and can be centrifuged at $\mathrm{pH}$ 7.4.

\section{RESULTS AND DISCUSSION}

Iron strongly increased the value of $\mathrm{P}_{1 / 2}$ for both types of melanin (Figs. 2A, C and 3A). Such an effect of iron was fast in the case of free salt of iron (III) or iron (III) complex with ADP and in all melanin samples with iron (II). On the other hand, iron (III) complex with citrate caused a very slow increase of half-power $\left(\mathrm{P}_{1 / 2}\right)$, especially in the case of DMt (Fig. 3A). The corresponding kinetics very well correlated with the decrease of iron content in the supernatant from DMt (Fig. 3B). The results indicate that $\mathrm{P}_{1 / 2}$ is a good indicator of iron binding by melanin. Interestingly, the addition of iron (II) to DMa resulted in a strong, slightly asymmetric EPR signal at $g=4.3$ typical for iron (III) complex with melanin (Sarna et al., 1981). The signal was similar to that observed when iron (III) was added to melanin (Fig 2D). This signal was almost independent of the presence of oxygen (Fig. 2B) The data suggest that the binding of iron (II) is accompanied by its rapid oxidation and that this process is independent of oxygen. Therefore, we checked the susceptibility of iron (III) bound to melanin to photosensitized reduction in rose bengal/ $\beta-\mathrm{NADH}$ oxygen-free system, where two strongly reducing radicals (Rose Bengal- and NAD) are formed (Lambert et

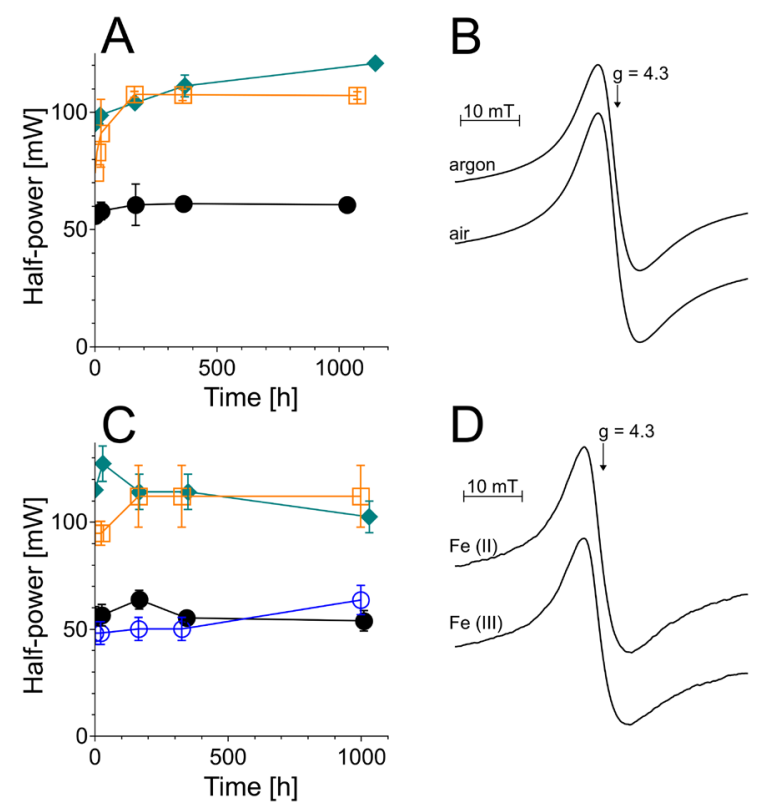

Figure 2. The interaction of iron with DMa.

Time-dependent changes of half-power $(\mathbf{A}, \mathbf{C})$ in samples containing $2 \mathrm{mg} / \mathrm{ml} \mathrm{DMa}$. Iron was added in complex with citrate (A) or as a free salt (C). Filled circles - control melanin without iron, open circles - control melanin without iron treated analogously as melanin with iron (III), filled diamonds - melanin with iron (II), open squares - melanin with iron (III). B, D - EPR signals of highspin iron (III) in samples with added iron (II) in anaerobic and aerobic conditions (B) or with added iron (II) and iron (III) in aerobic conditions (D)
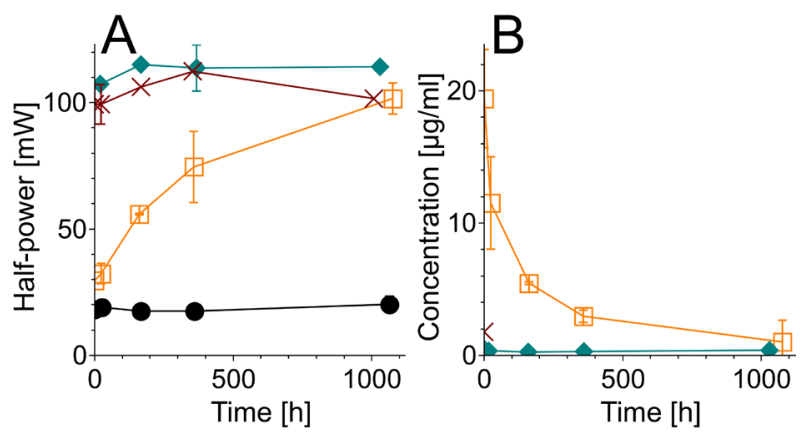

Figure 3. The kinetics of iron binding by DMt.

Time-dependent changes of half-power (A) or iron concentration in the supernatant (B) in samples containing $2 \mathrm{mg} / \mathrm{ml} \mathrm{DMt}$. Iron was added in complex with citrate except for the sample marked by crosses. Filled circles - control melanin without iron, filled diamonds - melanin with iron (II), open squares - melanin with iron (III), crosses - melanin with iron (III) added in complex with ADP.

al., 1990). For comparison, we used melanin-copper (II) complex in which copper (II) was previously shown to be reduced in such system (Korytowski \& Sarna, 1990). In the dark, DMa with $1 \%(\mathrm{w} / \mathrm{w})$ iron showed EPR signal typical for $\mathrm{Fe}(\mathrm{III})$-melanin complex (Fig. 4A), while DMa with $1.14 \%$ (w/w) copper exhibited EPR signal typical for $\mathrm{Cu}(\mathrm{II})-$ melanin complex (Fig. 4B) with $\mathrm{g}_{\mathrm{H}}=2.27$ (Froncisz et al., 1980). Although the irradiation of $1 \mathrm{mg} / \mathrm{ml} \mathrm{DMa}$ with $1.14 \%$ (w/w) $\mathrm{Cu}$ in the presence of $0.5 \mathrm{mM}$ rose bengal and $2.5 \mathrm{mM} \beta-\mathrm{NADH}$ caused almost complete disappearance of copper (II) EPR signal (Fig. 4B), the reducing radicals formed by the interaction of the excited triplet state of rose bengal with $\mathrm{NADH}$ had only a little effect on iron (III) EPR signal when iron was bound to melanin. In such samples, five times higher concentration of $\beta-\mathrm{NADH}$ was necessary for the photoreduction of iron (III) (Fig. 4A). It seems that photoreduction of iron (III) is possible only after the depletion of the redox capacity of melanin. It indicates that melanin is able to oxidize the bound iron (II). Although in the previous studies it was demonstrated that melanin reduces iron (III) to iron (II) (Korytowski et al., 1987; Pilas et al., 1988), it is important to stress that the ability of melanin to reduce iron (III) was shown either in the presence of EDTA which prevented iron binding by melanin or at low concentration of melanin with part of the iron remaining unbound. However, in this study citrate and ADP were used. Iron (II) could
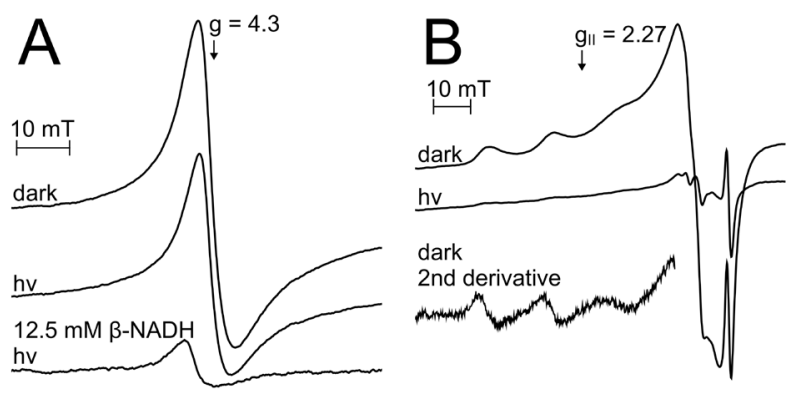

Figure 4. Photoreduction of iron (III) and copper (II) complexed with melanin.

EPR spectra of iron (III) (A) and copper (II) (B) bound to DMa in the dark and after 20 minutes of irradiation with $50 \mathrm{~mW} / \mathrm{cm}^{2}$ (516-586 nm) light. Samples were buffered in PBS and contained $1 \mathrm{mg} / \mathrm{ml}$ DMa with $1 \%$ (w/w) iron (III) (A) or Cu (II) (B), $5 \mathrm{mM}$ rose bengal and, except for the sample marked as "12.5 mM $\beta-\mathrm{NADH}^{\prime}$, $2.5 \mathrm{mM} \beta-\mathrm{NADH}$. The value of $\mathrm{g}_{\|}$for $\mathrm{Cu}$ (II) was determined from the second derivative of EPR signal acquired in the dark. 
be easily bound by melanin in the presence of citrate as shown in Figs. $2 A$ and $3 \mathrm{~A}$. Importantly, reduced melanin subunits (catechols) are more hydrophilic and thus more exposed to the external environment than oxidized forms (ortho-quinones), which are expected to be rather inside the polymer. Therefore, it can be postulated that melanin is able to reduce unbound iron (III) but iron (II) complexed with melanin is rapidly oxidized by this polymer. This conclusion is in accordance with the observable slow kinetics of iron (III) binding by melanin in the presence of citrate (Fig. 3A, B). Iron (III) forms a stronger complex with citrate than iron (II) and cannot be bound by melanin but melanin reduces iron (III) complexed with citrate. Then, iron (II) is bound by melanin and finally, melanin oxidizes iron (II). The reduction of iron (III) seems to be the slowest process that controls the rate of iron (III) binding by melanin in the presence of citrate.

In conclusion, although melanin acts as an electron donor for iron (III) that is not bound to this polymer, the dominant form of iron complexed with melanin is iron (III). This phenomenon can be explained by the fact that the reduced melanin subunits (catechols) are more hydrophilic and thus more exposed to the external environment than the oxidized forms of the melanin subunits (ortho-quinones), which are expected to be rather hidden inside the polymer. Binding of iron (III) by melanin can be essential for antioxidant action of melanin because such iron cannot participate in Fenton reaction. On the other hand, oxidative modification of melanin, induced by light or hydrogen peroxide may increase the one-electron reduction potential of the iron (III) bound to melanin and expose the iron ions to physiological reductants, such as ascorbate and glutathione. We postulate that under such conditions, iron (III) bound to oxidatively modified melanin could be relatively easily reduced and participate in the further degradation of melanin.

\section{REFERENCES}

Altenbach C, Greenhalgh DA, Khorana HG, Hubbell WL (1994) A collision gradient method to determine the immersion depth of nitroxides in lipid bilayers: application to spin-labeled mutants of bacteriorhodopsin. Proc Natl Acad Scie U S A 91: 1667-1671. https:// doi.org/10.1073/pnas.91.5.1667

Beatty S, Koh H, Phil M, Henson D, Boulton M (2000) The role of oxidative stress in the pathogenesis of age-related macular degeneration. Survey Ophthaly 45: 115-134. https://doi.org/10.1016/s00396257(00)00140-5

Brenner M, Hearing VJ (2008) The protective role of melanin against UV damage in human skin. Photochemi Photobiol 84: 539-549. https://doi.org/10.1111/j.1751-1097.2007.00226.x

Felix CC, Hyde JS, Sarna T, Sealy RC (1978) Interactions of melanin with metal ions. Electron spin resonance evidence for chelate complexes of metal ions with free radicals. I Am Chem Soc 100: 39223926. https://doi.org/10.1021/ja00480a044

Froncisz W, Sarna T, Hyde JS (1980) $\mathrm{Cu}^{2+}$ probe of metal-ion binding sites in melanin using electron paramagnetic resonance spec- troscopy. I. Synthetic melanins. Arch Biochem Biophys 202: 289-303. https://doi.org/10.1016/0003-9861(80)90430-0

d'Ischia M, Wakamatsu K, Cicoira F, Di Mauro E, Garcia-Borron JC, Commo S, Galván I, Ghanem G, Kenzo K, Meredith P, Pezzella A, Santato C, Sarna T, Simon JD, Zecca L, Zucca FA, Napolitano A, Ito S (2015) Melanins and melanogenesis: from pigment cells to human health and technological applications. Pigment Cell Melanoma Res 28: 520-544. https://doi.org/10.1111/pcmr.12393

Kaczara P, Zaręba M, Herrnreiter A, Skumatz CMB, Ządło A, Sarna T, Burke JM (2012) Melanosome-iron interactions within retinal pigment epithelium-derived cells. Pigment Cell Melanoma Res 25: 804 814. https://doi.org/10.1111/pcmr.12008

Korytowski W, Pilas B, Sarna T, Kalyanaraman B (1987) Photoinduced generation of hydrogen peroxide and hydroxyl radicals in melanins. Photochem Photobiol 45: 185-190. https://doi. org/10.1111/j.1751-1097.1987.tb05362.x

Korytowski W, Sarna T (1990) Bleaching of melanin pigments. Role of copper ions and hydrogen peroxide in autooxidation and photooxidation of synthetic dopa-melanin. J Biol Chem 265: 12410-12416.

Lambert C, Sarna T, Truscott TG (1990) Rose bengal radicals and their reactivity. J Chem Soc Faraday Trans 86: 3879-3882. https://doi. org/10.1039/FT9908603879

Meredith P, Sarna T (2006) The physical and chemical properties of eumelanin. Pigment Cell Res 19: 572-594. https://doi.org/10.1111/ j.1600-0749.2006.00345.x

Noonan FP et al (2012) Melanoma induction by ultraviolet A but not ultraviolet B radiation requires melanin pigment. Nat Communi 3: 1-10. https://doi.org/10.1038/ncomms1893

Pilas B, Sarna T, Kalyanaraman B, Swartz HM (1988) The effect of melanin on iron associated decomposition of hydrogen peroxide. Free Radic Biol Med 4: 285-293. https://doi.org/10.1016/08915849(88)90049-4

Sarna T (1992) Properties and function of the ocular melanin - a photobiophysical view. J Photochem Photobiol B, Biol 12: 215-258. https:// doi.org/10.1016/1011-1344(92)85027-r

Sarna T, Burke JM, Korytowski W, Rózanowska M, Skumatz CMB, Zareba A, Zareba M (2003) Loss of melanin from human RPE with aging: possible role of melanin photooxidation. Exp Eye Res 76: 89-98. https://doi.org/10.1016/s0014-4835(02)00247-6

Sarna T, Korytowski W, Pasenkiewicz-Gierula M, Gudowska E (1981) Ion-exchange studies in melanins. In Proceedings of the 11th International Pigment Cell Conference, Sendai, Seiji M ed. pp 23-29. University of Tokyo Press: Tokyo

Szewczyk G, Zadlo A, Sarna M, Ito S, Wakamatsu K, Sarna T (2016) Aerobic photoreactivity of synthetic eumelanins and pheomelanins: generation of singlet oxygen and superoxide anion. Pigment Cell Melanoma Res 29: 669-678. 23-29 https://doi.org/10.1111/pcmr.12514

Wood SR, Berwick M, Ley RD, Walter RB, Setlow RB, Timmins GS (2006) UV causation of melanoma in Xiphophorus is dominated by melanin photosensitized oxidant production. Proc Natl Acad Sci U S A 103: 4111-4115. https://doi.org/10.1073/pnas.0511248103

Zecca L, Casella L, Albertini A, Bellei C, Zucca FA, Engelen M, Zadlo A, Szewczyk G, Zareba M, Sarna T (2008) Neuromelanin can protect against iron-mediated oxidative damage in system modeling iron overload of brain aging and Parkinson's disease. I Neurochem 106: 1866-1875. https://doi.org/10.1111/j.1471-4159.2008.05541.x

Zecca L, Zucca FA, Wilms H, Sulzer D (2003) Neuromelanin of the substantia nigra: a neuronal black hole with protective and toxic characteristics. Trends Neurosci 26: 578-580. https://doi. org/10.1016/j.tins.2003.08.009

Zadlo A, Pilat A, Sarna M, Pawlak A, Sarna T (2017) Redox active transition metal ions make melanin susceptible to chemical degradation induced by organic peroxide. Cell Biochemi Biophys 75: 319-333. https://doi.org/10.1007/s12013-017-0793-6

Żądło AC (2019) Application of transition metal ions in a study of photoinduced modifications of melanin. Acta Biochim Pol 66: 237241. https://doi.org/10.18388/abp.2018_2802 